\title{
Estudios
}

\section{¿Qué concepto de identidad personal para la cristología?}

\author{
Xavier Morales \\ FACULTAD DE TEOLOGÍA \\ Pontificia Universidad Católica de Chile \\ xavier.morales@uc.cl
}

Resumen: La cristología pretende contestar a la pregunta por la identidad de la persona de Jesús de Nazaret. El presente ensayo intenta aclarar las precomprensiones del concepto de identidad personal y su influencia en la manera de responder a la pregunta cristológica. Después de un panorama histórico de contextualización, el autor parte de una descripción fenomenológica de la identidad de Jesús para determinar sus rasgos esenciales: su mediatez, su orientación retrospectiva, su dimensión paradójica. La reflexión desemboca en el umbral de la teología trinitaria, con consideraciones acerca del "sí" divino.

Palabras clave: Jesucristo, persona, identidad, filosofía, cristología

Abstract: Christology is the attempt to answer the question about the identity of the person of Jesus of Nazareth. The present essay tries to clarify the pre-comprehensions of the concept of personal identity and their influence in the way one answers the Christological question. After a historical overview which will serve as context, the autor starts from a phenomenological description of Jesus' identity in order to determine its essential features: its mediateness, its restrospective orientation, its paradoxical dimension. The reflection reaches the treshold of Trinitarian theology, with considerations on the divine "self".

Keywords: Jesus-Christ, person, identity, philosophy, Christology 


\section{INTRODUCCIÓN}

La cristología pretende contestar a la pregunta por la identidad de la persona de Jesús de Nazaret. Sin embargo, esta pretención está condicionada por la manera de concebir la identidad personal en general. La pregunta teológica requiere una aclaración conceptual previa. El presente ensayo no pretende ir más allá de esta aclaración: su lugar, por lo tanto, es, por así decirlo, una cristología fundamental o transcendental, aunque en un sentido distinto a la "cristología transcendental” de Karl Rahner.

Para llegar a ese fin, se dará un rápido y selecto panorama histórico de la correlación entre concepto de identidad personal y cristología (I). Este panorama permitirá presentar algunos de los problemas que la segunda parte del ensayo intentará resolver para deducir un concepto de identidad personal adecuado para la cristología (II). Sin embargo, esta deducción partirá ante todo de una descripción fenomenológica de la identidad de Jesús, para determinar sus rasgos esenciales: su mediatez (II.1), su orientación retrospectiva (II.2), su dimensión paradójica (II.3). La reflexión se concluirá con una reformulación crítica del concepto de "pre-existencia" como "trans-existencia”. Una apertura (III) integrará la problemática cristológica dentro de la problemática trinitaria de la identidad del "sí" divino.

\section{ACLARACIÓn CRítica PREVIA DEL CONCEPTO DE IDENTIDAD PERSONAL}

¿A qué me refiero cuando hablo del "concepto de identidad personal adecuado para la cristología”? Más o menos a lo que se llamó, en la Edad Media, "el principio de individuación", pero aplicado específicamente al individuo personal: lo que hace que uno sea la persona que uno es y no otra.

La historia del concepto de "persona" en su correlación con la teología trinitaria ha sido bastante profundizada en el último siglo ${ }^{2}$. En cambio, todavía falta una reflexión de cristología fundamental sobre el concepto de "identidad".

1 Ver por ejemplo J. J. E. García, Introduction to the Problem of Individuation in the Early Middle Ages (München ${ }^{2} 1988$ ).

2 Ver, entre muchas contribuciones, A. Milano, Persona in teologia. Alle origini del significato di persona nel cristianesimo antico (Nápoles 1984) y E. HousseT, La vocation de la personne. L'histoire du concept de personne de sa naissance augustinienne à sa redécouverte phénoménologique (París 2007). 
Hans Urs von Balthasar, en páginas centrales para su propia cristología ${ }^{3}$, distingue entre 1) el individuo, como diferencia última en la especie; 2) el sujeto espiritual (Geistsubjekt), en que la unicidad individual se refleja en una conciencia; y 3) la persona como "tú" interpelado por el "yo" absoluto, Dios mismo. Me inspiraré de esta distinción para ordenar mi panorama.

\section{La identidad del individuo}

En su Metafísica $a^{4}$, Aristóteles aborda varias veces el significado del concepto de "identidad" o "ser lo mismo" (tauton). El filósofo establece un vínculo estrecho entre "ser", "ser uno" y "ser lo mismo" . Por lo tanto, se puede decir de "mismo" lo que se dice de "ser" y "uno", o sea "que se dicen en muchos sentidos".

Básicamente, Aristóteles distingue entre cosas "mismas por accidente" y “mismas según sî”. Entre las cosas que son esencialmente idénticas,

se dice que son las mismas: 1) aquellas cosas cuya materia es una, ya específica ya numéricamente; y 2) aquellas cosas cuya substancia es una. De este modo, es evidente que la identidad es, en alguna manera, unidad del ser, bien de una pluralidad, bien de algo considerado como una pluralidad, como cuando algo se dice lo mismo que sí mismo․

El vínculo entre "ser", "uno" y "lo mismo" es muy importante. Por una parte, el concepto de identidad se refiere al concepto de unidad, que el mismo Aristóteles reformula como indivisibilidad. Definir la identidad de algo o alguien, por lo tanto, es definir cómo esta cosa o esta persona es una. De ahí que, en cristología, la cuestión del modo de la unidad entre los varios aspectos de la personalidad de Jesús sea preponderante.

Por otra parte, el concepto de identidad se refiere al concepto de ser y queda marcado por la determinación de un "sentido primero" del ser

3 H. U. von Balthasar, Teodramática, 3. Las personas del drama: el hombre en Cristo (tr. esp., Madrid 1993) 190-195 = Theodramatik, II. Die Personen des Spiels, 2. Die personen in Christus (Einsiedeln 1978) 186-191.

4 Ver sobre todo Metafisica, Delta, 9 y Iota, 3. En este artículo, cuando no se menciona una determinada traducción castellana, la traducción es mía.

5 "El ser y el uno son la misma cosa" (Metafisica, Gamma, 2, 1003b22-23); "el mismo [...] es del uno" (Iota, 3, 1054a29-31).

6 Para el ser: Gamma, 2, 1003a33; para el uno: ibidem, 1004a22; y para el mismo: ibidem, $1004 a 27$ y Iota, 3, 1054a32-33.

7 Delta, 9, 1018a5-9. 
como substancia ${ }^{8}$. La identidad es, en el sentido estricto, identidad de una substancia. Recíprocamente, la substancia es, según Platón", "siempre lo mismo según la misma perspectiva”. Definir la identidad de una cosa o de una persona consiste, por lo tanto, en distinguir lo substancial en ella, lo que no cambia a través de los cambios. En el caso del "ser viviente", dice Platón ${ }^{10}$, este elemento es el "alma" detendrá de ser (es "inmortal"). Escapa, pues, a los dos cambios mayores que son el pasaje del no ser al ser, y del ser al no ser. Reviste, a lo largo de su existencia, varias "formas" (eidē), o sea varios "cuerpos", para los cuales es "principio de movimiento". En Platón, este principio de movimiento es "lo que se mueve a sí mismo". Cuando Aristóteles sustituye a este principio autokinèton un "algo que mueve sin ser movido, siendo eterno, substancia y operación actual" 12 , acaba de definir la identidad como inmutabilidad perfecta.

En esta representación antropológica, la identidad, como permanencia substancial, es asumida por el alma, o su parte más noble, el nous, mientras que el cambio es atribuido al cuerpo. En el modelo cristológico llamado "logos-sarx", la distinción entre alma y cuerpo es trasladada a la relación entre el Logos divino y la humanidad en Jesús, de suerte que la humanidad de Jesús es una humanidad sin alma ${ }^{13}$.

El paso conceptual de la identidad como unidad-indivisibilidad al individuo (atomon) es sencillo. El individuo es precisamente el resto indivisible del proceso

8 Zeta, 1, 1028a30-31.

9 Platón, Fedón, 78c9-d2. Sobre el tema de la reducción del sentido del ser a la substancia, y su consecuencia para el concepto de persona, ver por ejemplo mis comentarios en La relativité de Dieu. La contribution de la Process Theology à la théologie trinitaire (París 2017) 9-12.

10 Platón, Fedro, 245c-249d.

11 La síntesis de Gert Theissen, en el primer capítulo de su Erleben und Verhalten der ersten Christen. Eine Psychologie des Urchristentums (Gütersloh 2007), dedicado a "la invención del hombre interior en la Antigüedad", permite destacar que la representación del alma como principio de la identidad personal es el resultado de un proceso histórico complejo.

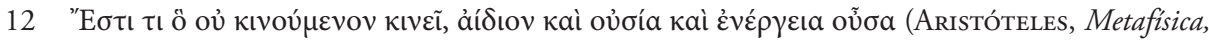
Lambda, 1072a25).

13 Ejemplos en Eusebio de Cesarea, Teología eclesiástica, I, 20, 31-52, en los teólogos arrianos que combate Eustacio de Antioquía (ver Contra los locos seguidores de Arrio y sobre el alma, en Eustathii antiocheni, patris nicaeni, opera quae supersunt omnia, ed. J. H. DeCLERCK [CCSG 51; Turnhout 2002], frag. 1 y frag. 19b), en Eudoxio de Constantinopla (en Fr. Diekamp, Doctrina Patrum de Incarnatione Verbi. Ein Griechisches Florilegium aus der Wende des 7. und 8. Jahrhunderts [Münster ${ }^{2} 1981$ ] 64-65) y en ApOLINAR DE LAODICEA. 
de subdivisión de los géneros y de las especies por diferencias (sean genéricas, específicas o, precisamente, individuales), descrito por Porfirio en su Introducción a las categorías de Aristóteles $^{14}$. Boecio, en su pequeño tratado de cristología, aplica las definiciones de Porfirio y define la persona como "substancia individual de naturaleza racional"15. La naturaleza, en cambio, es la "diferencia específica" La persona, en cuanto individuo, substantia o hypóstasis (según la equivalencia propuesta por el mismo Boecio) "proporciona un fundamento (subjectum) para los accidentes, para que puedan existir" 17 . Por lo tanto, la identidad de Cristo se funda en la sustancialidad del "sujeto", que asume las naturalezas como conjuntos de propiedades específicas. Boecio no se plantea cómo dos diferencias específicas pueden subsistir en un mismo sujeto, cuando, por definición, dos especies ubicadas "bajo" un mismo género se excluyen.

En Oriente, la representación de la persona como hypóstasis es esencialmente la misma. En los capítulos cristológicos de su Fe ortodoxa (46-81), Juan Damasceno recoge la tradición patrística. Una naturaleza no puede existir sino en un sujeto individual. Por lo tanto, "el Verbo de Dios prestó una hypóstasis a la carne" 18 y "hizo subsistir en su propia bypóstasis [...] una carne dotada de un alma racional e intelectual"19. La identidad de Cristo se funda en la sustancialidad de la hypóstasis, aislada de las propiedades de sus naturalezas. Frente a esta concepción abstracta de la hypóstasis, Juan Damasceno no se plantea en qué sentido la naturaleza divina es "propia" del Verbo y la naturaleza humana es sólo "apropiada" por él, sino con la diferencia entre eternidad y temporalidad.

La Edad Media retoma la cuestión de la identidad bajo la problemática del "principio de individuación". ¿Cómo se diferencian los individuos dentro de su especie, si todos tienen las mismas propiedades comunes a la especie? La mayoría de los escolásticos siguen la solución aristotélica de la individuación por la materia:

14 Porfirio, Isagoge o Introducción a las categorias de Aristóteles, II, 11-12 (Porphyre, Isagoge. Texte grec, Translatio Boethii [París 1998]) 8.

15 Boecio, Sobre la persona y las dos naturalezas contra Eutiques y Nestorio, III, 1 (BoÈCE, Traités théologiques [París 2000] 74).

16 Boecio, Sobre la persona..., I, 24 (Bò̀ce, Traités théologiques..., 70).

17 Boecio, Sobre la persona..., III, 18 (BoÈCE, Traités théologiques..., 74).

18 Juan Damasceno, La Fe ortodoxa, 46, 1. 30 (Jean Damascène, La foi orthodoxe 45-100 [SC 540; París 2011] 16).

19 Juan Damasceno, La Fe ortodoxa, 46, 1. 32 -34 (Jean Damascène, La foi orthodoxe..., 16) 
Sócrates es otro que su padre por la materia, que es otra, pero idéntico a él por la forma, pues la forma es indivisible ${ }^{20}$.

No es necesario explicar por qué esta solución no es adecuada para pensar la identidad cristológica.

Juan Duns Escoto se opone a esta teoría ${ }^{21}$. Según él, la diferencia individual no viene ni de la materia, ni de la forma, puesto que ambas son comunes a varios individuos, sino de una "entidad de la singularidad"22, "una entidad positiva que determina esencialmente la naturaleza" común a todos los individuos de una misma especie "para producir la singularidad"23.

Una tercera solución, expuesta por primera vez por Porfirio, reaparecerá en la Edad Moderna. Según Porfirio, el individuo se diferencia de los otros individuos por ser el punto de coincidencia singular de propiedades comunes a determinadas clases de individuos.

"Individuo" se dice de Sócrates, este blanco, este hijo de Sofronisco que viene [...]. "Individuo" se dice de estas cosas, porque cada una es compuesta de propiedades cuya reunión (athroisma) no ocurrirá jamás idéntica en otra $\cos ^{24}$.

En Porfirio, la reunión de propiedades produce el individuo por su agregación a la definición de la naturaleza común a todos los individuos de

20 Aristóteles, Metafísica, Zeta, 8, 1034a. Comentarios, entre muchos, en B. Pinchard, "Le principe d'individuation dans la tradition aristotélicienne", en COLL., Le problème de l'individuation (París 1991) 27-50.

21 Ver sobre todo Juan Duns Escoto, Ordinatio, 1. II, d. 3, p. 1, q. 5 y 6; Quaestiones subtilissimae super libros Metaphysicorum Aristotelis, 1. VII, q. 13. Comentario por G. SondaG, Duns Scot. Le principe d'individuation (París 2005).

22 Ord. II, d. 3, p. 1, q. 6, $\$ 188$.

23 Ord. II, d. 3, p. 1, q. 6, $\$ 142$.

24 Porfirio, Isagoge o Introducción a las categorías de Aristóteles, II, 15 (Porphyre, Isagoge..., 9). Ver, entre otros, los comentarios de C. Erismann, "L'individualité expliquée par les accidents. Remarques sur la destinée 'chrétienne' de Porphyre", en Compléments de substance. Études sur les propriétés accidentelles offertes à Alain de Libera, ed. C. ERISMann y A. SCHNiezind (París 2008) 51-66. R. Sorabji se refirió a la solución de Porfirio con la expresión Bundle Theory, originalmente acuñada para referirse al empirismo moderno, en Matter, Space and Motion. Theories in Antiquity and Their Sequel (Duckworth 1988; repr. Chicago University Press, Bloomsbury 2013) 44-59 e ÍDEM, Self. Ancient and Modern Insights about Individuality, Life, and Death (Oxford 2006) 137-156. 
la especie. En el marco del empirismo moderno, David Hume niega que exista una substancia en que "se supone que las calidades particulares son inherentes". Sólo queda entonces la "colección de ideas simples, unidas por nuestra imaginación"25. La identidad personal, el self, "sólo es un manojo (bundle) o colección de diversas percepciones" ${ }^{26}$.

\section{La identidad del sujeto espiritual}

En la definición de Boecio, la persona, como especificación del individuo con la determinación de racionalidad, ocupaba la última rama del árbol de Porfirio. René Descartes da la vuelta a todo el sistema y coloca el individuo racional al principio de todo conocimiento:

Conocí que yo era una substancia cuya esencia o naturaleza entera no es otra cosa que pensar ${ }^{27}$.

Descartes todavía designa el individuo racional como substantia, pero el sentido de substantia se transforma. La substancia ya no es lo que permanece bajo las propiedades para hacerles existir. Ya no es sujeto en el sentido de un "sustrato". La substancia, en cuanto racional, es lo que acompaña todo pensar. Es sujeto en el sentido de una "conciencia" 28 .

El idealismo trascendental inaugurado por Immanuel Kant se da por tarea, a partir de Johann Gottlieb Fichte ${ }^{29}$, la descripción del sujeto que piensa como principio del saber absoluto. La descripción más famosa es la de la Fenomenología del Espiritu (1807) de Georg Wilhelm Friedrich Hegel. El Sistema del idealismo trascendental (1800) de Friedrich Wilhelm Joseph Schelling ${ }^{30}$ proporciona una síntesis más breve y de lectura más accesible,

25 D. Hume, Treatise of the Human Nature (1737), I, I, vi.

26 D. Hume, Treatise of the Human Nature, I, IV, vi.

27 R. Descartes, Discours de la méthode (1637), IV (Vrin, París 1979) 91 (mi traducción).

28 Para J. Locke, An Essay concerning humane understanding (21694), II, XXVII, 12, "La conciencia (consciousness) hace la identidad personal"; II, XXVII, 19: "El sí mismo (Self) depende de la conciencia, no de la substancia”.

29 Grundlage der gesamten Wissenschaftslehre, obra publicada en fascículos entre 1794 y 1795.

30 F. W. J. Scheluing, System des transscendentalen Idealismus (1800), en Werke, 9/1 (Stuttgart 2005); Sistema del idealismo transcendental (tr. esp. de J. Rivera de Rosales, y V. López Domínguez, Barcelona $\left.{ }^{2} 2005\right)$. Ver los estudios de X. Tillietre sobre la cristología de los filósofos idealistas, entre los cuales: La christologie idéaliste (col. Jésus et Jésus-Christ; París 1986); El Cristo de la filosofia: prolegómenos a una cristología filosófica, tr. esp. (Bilbao 1994); Le Christ des philosophes. Du maître de sagesse au divin Témoin (Namur 1993). Para F. Hegel, ver E. Brito, La christologie de Hegel, Verbum Crucis (París 1983). 
que tuvo mucha influencia en una obra importante para la cristología, la Vida de Jesús de David Friedrich Strauss ${ }^{31}$.

El punto de partida de Descartes era la res cogitans. Suspendidas todas las certidumbres acerca de la existencia real de los objetos pensados por esta res cogitans, el único objeto que le queda es ella misma - el propio sujeto del pensar. Aquí aparece un nuevo sentido de la identidad: la coincidencia del objeto con el sujeto. Esta identidad es propia del sujeto espiritual, que es esencialmente un sí mismo pensado, una "autoconciencia" (Selbst-bewusst-sein). Ningún otro sujeto ("tú", "él", etc.) que el sujeto que coincide con sí mismo tiene acceso a este sí, con lo cual, este sí no es otro que el "yo mismo".

Por el acto de la autoconciencia ha de surgir en nosotros un concepto y éste no es otro que el del Yo. Al convertirme en objeto para mí por medio de la autoconciencia, se origina para mí el concepto del Yo, y, a la inversa, el concepto del Yo sólo es el concepto del devenir sí mismo objeto (Selbstobjektwerdens) ${ }^{32}$.

De esta concepción del sujeto-Yo como resultado de un acto cuyo agente es el mismo, se deduce que su identidad no proviene de determinaciones extrínsecas. El yo se auto-produce. Es creador de sí mismo. De ahí que el concepto clave del idealismo trascendental sea "la libertad"33.

La mayor ventaja de la definición del sujeto espiritual como autoconciencia es la superación de las aporías acerca de su identidad. Ya no hace falta recurrir a modelos complejos de unión entre elementos antagónicos, como la "unión hipostática" de las dos naturalezas divina y humana. La identidad del sujeto ya existe en el sujeto como su actuar propio: "El yo no es nada más que aspiración a ser igual a sí mismo" ${ }^{34}$.

El problema, como lo nota Balthasar, es, en el proceso, "la pérdida,

31 En la sección final de Das Leben Jesu, kritisch bearbeitet (Tübingen ${ }^{1} 1835$ ), $\$ 140-147$, D.F. Strauss aplica la filosofía de la religión de Schelling y Hegel a la cristología. Para las fuentes filosóficas de Strauss, ver la introducción editorial a D. F. Strauss, The Christ of Faith and the Jesus of History. A Critique of Schleiermacher's Life of Jesus, tr. ingl. de L. E. Keck (Philadelphia 1977).

32 F. W. J. Schelling, Sistema del idealismo transcendental (Barcelona $\left.{ }^{2} 2005\right) 174$.

33 Ver F. W. J. Schelling, Philosophische Untersuchungen über das Wesen der menschlichen Freiheit und die damit zusammenhängenden Gegenstände (1809).

34 F. W. J. Schelling, Sistema del idealismo transcendental, 199. 
sufrida como por descuido, del individuo como persona"35, hasta su último avatar en el colectivismo marxista-soviético. De hecho, la persona, en cuanto Yo individual y empírico, se contrapone, como su limitación, al Yo absoluto e infinito, identificado con "lo divino", concebido entonces como "lo impersonal" ${ }^{36}$. El marco teológico es explícitamente panteísta: "Entonces, Dios es realmente todo en todo, el panteísmo es verdadero" ${ }^{37}$. La consecuencia para la cristología es que Jesús ya no es un individuo singular, sino una presentación del ideal (Schelling) o de la idea (Hegel) de la unidad entre lo infinito y lo finito, recogida "en la conciencia general"38.

\section{La identidad de la persona}

En varios pasajes de su Sistema del idealismo trascendental, Schelling confiesa que, si bien su "sistema" explica la necesidad de una "limitación" del Yo infinito en un Yo finito, la "determinación" de esta limitación, la "individualidad" en sí, "es lo inconcebible e inexplicable de la filosofía”" ${ }^{9}$. Søren Kierkegaard fundará su crítica del idealismo en esta intuición de la irreductibilidad de lo que él llama "el individuo" (den Enkelte) al "espécimen" 40 (Exemplar). La persona no se puede reducir, ni a al resultado de la división última dentro de una clase, o sea, a la "individualización”, ni al momento intermedio de la auto-posición de sí del sujeto absoluto. Por consiguiente, la identidad personal debe interpretarse también a partir de la irreductibilidad como carácter propio de la persona.

Al principio del siglo $\mathrm{xx}$, se dio otro giro de largo alcance en la comprensión de la identidad personal, en la corriente filosófica llamada "personalismo" 41 . La identidad personal ya no se piensa como suma de propiedades, permanencia en el tiempo y el espacio o autoconciencia,

35 H. U. von Balthasar, Teodramática, 1. Prolegómenos (1973) (tr. esp. de E. Bueno de la Fuente y J. Camarero, Madrid 1990), 541.

36 F. W. J. Schelling, Stuttgarter Privatvorlesungen, en Sämtliche Werke, 7 (Stuttgart 1860) 468.

37 F. W. J. Schelling, Stuttgarter Privatvorlesungen, 484.

38 D. F. Strauss, Das Leben Jesu, 735.

39 F. W. J. Schelling, Sistema del idealismo transcendental, 215.

40 S. KierkegaARD, "Ese Individuo. Dos notas sobre mi labor como escritor", en Mi punto de vista (1859), tr. esp. de J. M. Velloso (Buenos Aires, $\left.{ }^{5} 1980\right)$, 128. La traducción por "individuo" es equívoca, de suerte que varios estudiosos prefieren especificar: "individuo singular".

41 El libro emblemático de esta corriente es M. Buber, Yo y Tú (1923) (tr. esp. de H. Crespo, Buenos Aires $\left.{ }^{2} 1960\right)$. Ver también, en el contexto de la teología dialéctica, F. Gogarten, Der Mensch zwischen Gott und Welt (Stuttgart 1952) 240: "la personalidad del ser humano [...] nunca puede ser otra cosa que la respuesta a la palabra de Dios". 
sino como ser-en-relación. El concepto de la persona como relación subsistente había sido propuesto por Tomás de Aquino, pero sólo para las personas divinas ${ }^{42}$. Ahora se extendía a las personas humanas y, recíprocamente, desembocaba en nuevas propuestas teológicas, tanto en el campo de la teología trinitaria como en el de la cristología.

Martin Buber declara: "En el principio es la relación”ł3. "La conciencia de $Y o$ " no es el fenómeno primitivo. "El Yo emerge, como elemento singular, de la descomposición de la experiencia primitiva" ${ }^{44}$ del "Yo-Tú". De ahí resulta que "el hombre se torna un Yo a través del Tü" ${ }^{45}$.

La cristología de Hans Urs von Balthasar" ${ }^{46}$ retoma el "principio dialogal" ${ }^{47}$ del personalismo. El paso del individuo al sujeto individual no basta para responder a la pregunta “¿Quién soy?”.

Allí donde Dios dice a un sujeto espiritual quién es éste para él, el Dios fiel y veraz, y donde en el mismo movimiento le dice para qué existe (pues le adjudica una misión acreditada por Dios), allí se puede decir de un sujeto espiritual que es persona ${ }^{48}$.

La identidad de Jesús se determina por su relación con Dios, en cuanto Hijo del Padre enviado al mundo. Esta relación trasciende las dos naturalezas. Jesús es Hijo de Dios tanto en su naturaleza humana como en su naturaleza divina. De hecho, en su naturaleza divina, esta identidad se funda en su procesión eterna, puesto que la relación de filiación constituye

42 Tomás de Aquino, Suma de Teología, I, q. 29.

43 M. Buber, Yo y Tú (Buenos Aires $\left.{ }^{2} 1960\right) 21$.

44 M. Buber, Yo y Tú, 24.

45 M. Buber, Yo y Tú, 29. Se podría comparar el "fenómeno primitivo de la relación" con el Mitdasein de M. Heidegger en Sein und Zeit (1927), I, 1, Iv, $\$ 26$ (Tübingen ${ }^{10} 1963$ ) 123: "pertenece al ser del Dasein, acerca del cual se trata para él en su propio ser, el ser-con-otros".

46 H. U. von Balthasar, Teodramática, 3. Las personas del drama: el hombre en Cristo (1978) (tr. esp. E. Bueno de la Fuente y J. Camarero, Madrid 1993), "cristología en perspectiva”. Ver también Hans Urs von Balthasar, "Zum Begriff der Person", en Homo creatus est, Skizzen zur Theologie V (Einsiedeln 1986) 93-102; C. I. CASAle Rolle, "La vigencia de la pregunta teológica por el término 'persona' para la imagen del hombre en la actualidad: el aporte de Hans Urs von Balthasar", en Teología y Vida 42 (2001) 399-439; A. MeIs, "La persona como singularidad concreta según Hans Urs von Balthasar", en Teología y Vida 42 (2001) 440-467.

47 H. U. von Balthasar, Teodramática, 1, 609-626.

48 H. U. von Balthasar, Teodramática, 3, 193-194. 
la segunda persona de la Trinidad ${ }^{49}$. En su naturaleza humana, la identidad de Jesús como Hijo de Dios se funda en su misión temporal, en la medida en que, singularmente en el caso de Jesús, la persona se identifica sin resto con la misión recibida de Dios ${ }^{50}$. Ahora bien, "la missio del Hijo es la forma económica de su eterna processio del Padre" ${ }^{51}$. Por lo tanto, se salvaguarda la identidad personal a través de las discontinuidades mayores que son la encarnación, la muerte y la resurrección, sin necesidad de suponer una substancia permaneciendo la misma a través de estos varios estados.

\section{HACIA UN CONCEPTO DE IDENTIDAD PERSONAL ADECUADO PARA LA CRISTOLOGÍA}

Tengo que confesar que la propuesta de Balthasar sigue siendo, para mí, la base de mi precomprensión del concepto de persona en general, como bipolaridad entre "ser-por-si" (identidad del sujeto espiritual) y "ser-en-relación" (identidad relacional o personal propiamente dicho) ${ }^{52}$. La persona es la substancia individual que se refleja en sí mismo como sujeto espiritual y recibe su determinación última de su relación con el otro absoluto, Dios. Fundando a la persona en Dios mismo, la concepción balthasariana parece particularmente adecuada para la cristología, cuya tarea principal consiste justamente en aclarar la relación de Jesús de Nazaret con Dios.

Sin embargo, incluso Balthasar parte de un concepto general de identidad personal, para aplicarlo luego a la persona de Jesús, con el riesgo de ocultar un dato presente en todos los testimonios que se conservan acerca de Jesús, y que el mismo Balthasar coloca en el centro de su cristología, o sea, la singularidad "impensable" de Jesús ${ }^{53}$.

49 Tomás de Aquino, Suma de teología, Ia, q. 40, a. 2, resp.

50 Ver C. I. Casale Rolle, El envio. Tema fundamental y estructura formal de la obra de Hans Urs von Balthasar (Santiago de Chile 1997).

51 H. U. von Balthasar, Teodramática, 3, 188.

52 Ver X. Morales, Dieu en personnes, 18-19, con el apartado de historia de la teología, 19-29, y la referencia a Ch. SсHÜTZ y R. SARACH, "El hombre como persona", en Mysterium Salutis. Manual de teología como historia de la salvación, vol. II, t. II (1965), dir. J. FeINER y M. LöHrer (tr. esp., Madrid 1969) 716-736, y L. SeNTIS, "Penser la personne", en Nouvelle revue théologique 116 (1994) 679-700.

53 Sobre la singularidad de Cristo, ver en particular Teología de la historia (tr. esp., Madrid 1959) 21 25 = Theologie der Geschichte. Ein Grundriss. Neue Fassung (Einsiedeln 1959) 13-17: "Das schlechthin Einmalige". Sobre su "impensabilidad", o sea, el hecho que no se deduce de lo general, ver H. U. von Balthasar, Gloria, 7. Nuevo Testamento (tr. esp., Madrid 1989) 33 = Herrlichkeit. Eine theologische Ästhetik, III, 2, Theologie, 2, Neuer Bund (Einsiedeln 1969) 32 (unausdenkbar). Ver también: "El Jesucristo real no puede ser inventado por hombres" (Teodramática, 3, 49; Theodramatik, II, 2, 38). Sobre la palabra unvordenklich, remito a la nota final de este ensayo. 
Por esta razón, me parece necesaria una aproximación al concepto de identidad personal que ponga entre paréntesis toda preconcepción y parta del mismo Jesús. Sólo así podrá el objeto final de la búsqueda determinar la forma conceptual en qué él quiere ser comprendido.

Ahora bien, la crítica histórica de los dos últimos siglos demostró que un acceso directo a Jesús de Nazaret no existe. Todo lo que se puede conocer de él está trasmitido por testigos que impusieron interpretaciones casi indisociables de sus testimonios. Al fin y al cabo, Rudolf Bultmann declaró rotundamente, hace casi un siglo, "en mi opinión, ya no podemos saber nada, casi, de la vida y la personalidad de Jesús" "54. Sin embargo, aquí no se trata del qué sino del cómo de la cristología. No se trata de entrar en el debate de la "búsqueda por el Jesús histórico", ni de contestar directamente a la pregunta cristológica. En lugar de deplorar la imposibilidad de disociar el objeto estudiado de las interpretaciones dadas por los que lo observan, hay que partir de este fenómeno: Jesús, percibido e interpretado como una persona. La metodología más adecuada para hacerlo consiste en suspender el juicio sobre las varias interpretaciones de este fenómeno, y observar qué concepto de identidad personal hace posibles estas interpretaciones. La fenomenología inaugurada por Edmund Husserl, cuando invita a regresar a "la cosa misma" 55 , no pretende llegar a la cosa en sí, en el sentido del noúmeno kantiano, opuesta a su apariencia engañosa ${ }^{56}$, sino a la cosa que se da a conocer al sujeto en sus intuiciones, el fenómeno, opuesta a las especulaciones sin fundamento real ${ }^{57}$. De todos modos, en la teología, el observador no tiene acceso al objeto estudiado, Dios, en sí, sino sólo tal

54 R. Bultmann, Jesús (1926) en R. Bultmann, Jesús - K. Jaspers, La desmitologización del Nuevo Testamento (tr. esp., Buenos Aires 1968) 12.

55 'Queremos retroceder a las 'cosas mismas'. Sobre intuiciones plenamente desenvueltas queremos llegar a la evidencia de que lo dado aquí [en los conceptos lógicos], en abstracción actualmente llevada a cabo, es verdadera y realmente lo mentado por las significaciones de las palabras" (E. Husserl, Investigaciones lógicas, II, 1, Investigaciones para la fenomenología y teoría del conocimiento, Introducción, 2 [1901] [tr. esp. de M. G. Morente y José Gaos, Madrid 2006] 218).

56 Ver I. Kant, Crítica de la razón pura, Analítica trascendental, Libro II, cp. III (2a edición, 1787), en Kants Gesammelte Schriften, Bd. 3 (Berlin 1904) 209.

57 No me corresponde exponer las acusaciones que los propios discípulos de Husserl llevaron contra el giro trascendental de su maestro (ver por ejemplo Roman INGARDEN, Controversy over the Existence of the World, I [tr. ingl., Frankfurt 2013] Preface, 19-24) y adopto la definición del fenómeno como "lo que se muestra en y desde sí (Heidegger), en lugar de dejarse constituir (Husserl)” (Jean-Luc Marion, Étant donné. Essai d’une phénoménologie de la donation [2a ed., París 1998] 9). 
como él se da a conocer en una aparición, o revelación, y en la medida que esta revelación, para ser recibida, necesita una interpretación proporcionada por la $f e$.

Además, reclamar un acceso "directo" a la identidad de Jesús reposa ya en algún o otro prejuicio acerca del concepto de identidad personal: sea que se la considere determinada por las circunstancias históricas, lamentablemente deformadas por las interpretaciones que rigen los documentos conservados; sea que se la considere determinada por su autoconciencia y, en este caso, objeto de conocimiento exclusivo y incomunicable del "yo".

Estas reflexiones preliminares ya proporcionan algunas pautas para la búsqueda de un concepto de identidad personal adecuado para la cristología. Para que no sea una especulación sin apoyo en la realidad, debe partir de la persona misma de Jesús; pero al mismo tiempo, debe reconocer que se accede a Jesús sólo de manera mediata. Como lo mostraré en un primer apartado, la dimensión mediata del acceso a Jesús recae también sobre su identidad personal. Se hablará de una identidad mediata. Un segundo apartado presentará otra dimensión importante de la identidad de Jesús expresada en las interpretaciones trasmitidas en el Nuevo Testamento: su dimensión retrospectiva. Este elemento conducirá a tratar de un problema clave: el problema de la temporalidad. Una aclaración crítica acerca del concepto tradicional de "pre-existencia” permitirá concluir en el umbral de la teología trinitaria.

\section{Una identidad mediata}

El concepto vulgar de identidad vincula dos cosas entre sí, y califica la segunda como "la misma" que la primera. Ahora bien, "mismo" es una palabra ambigua, como lo demuestran los análisis de Aristóteles presentados más arriba, y, más recientemente, entre otros, la propuesta de Paul Ricoeur ${ }^{58}$ de distinguir entre dos especies de identidad, la "mismidad", que implica una "permanencia en el tiempo", y la "ipseidad", o "mantenimiento de sí" a pesar de los cambios en el tiempo.

¿Es la persona de Jesús de Nazaret descrita por los documentos trasmitidos en el Nuevo Testamento "idéntica" a la persona de Jesús de Nazaret que existió en tiempos de Tiberio? A esta pregunta, la crítica histórica responde 
diciendo que estos documentos no presentan directamente al Jesús "histórico" sino una interpretación teológica que la oculta ${ }^{59}$.

Ahora bien, en el contexto del método fenomenológico, las interpretaciones teológicas de la identidad de Jesús se revelan, no como pantallas que ocultan al Jesús real, sino como aproximaciones a un fenómeno que, como lo explicaré en la última sección de este ensayo, da más que lo que aparece en él. Además, el hecho de que se acceda a Jesús mediante las interpretaciones de los que le conocieron coincide con un elemento convergente en estas interpretaciones: Jesús dejó su identidad abierta a la interpretación de los demás.

\section{Una identidad abierta a la interpretación de los demás}

En el Evangelio de Marcos, Jesús mismo nunca declina su identidad. Siempre deja que sea determinada por los demás. Basta recordar la pregunta que Marcos pone al centro de su Evangelio: "¿Y vosotros, quién decís que soy yo?" (Mc 8, 29). La respuesta dada por Simón Pedro, identificando a Jesús como "el Cristo", puede ser correcta, pero Jesús no la valida. Más precisamente: Jesús no deja que el que responde comunique su respuesta a otros (cf. Mc 1, 25.34.44 etc.). Éste podría ser el sentido del famoso "secreto mesiánico": dejar suspendida la respuesta a la pregunta acerca de la identidad de Jesús para que cada uno pueda volver a hacer, para su propia cuenta, la operación de identificar a Jesús, de dar a Jesús una identidad. Así, la identidad abierta de Jesús es una identidad que "intriga" ${ }^{0}$ al otro a quien Jesús aparece, que no se impone a él, pero, entregándose a él, le invita a comprometerse.

Unas de las consecuencias de la elección, por parte de Marcos, de la forma narrativa expresa perfectamente esta dimensión de apertura. La manifestación de la identidad de Jesús para el lector es mediatizada por los otros personajes, que son tantos "puntos de vista", para expresar facetas y percepciones distintas, acerca de Jesús.

59 A. Gesché, en el c. 2, "El Jesús de la historia y el Cristo de la fe", de Jesucristo. Dios para pensar VI (2001) (tr. esp. de J. M. Bernal, Salamanca 2002), toma de P. Ricoeur (Sí mismo como otro, estudio VI: "El sí y la identidad narrativa", 138-172) el concepto de "identidad narrativa" como término de mediación entre "identidad histórica" y "identidad dogmática". Ver los comentarios de A. Espezel, "La identidad narrativa de Jesús", en Communio (ed. arg.) 11/2 (2004) 27-35; ÍDEM, "La cristología dramática de Balthasar", en Teología y Vida 50 (2009) 305-318; X. MoraLES, "Pour introduire le concept d'identité dramatique de Jésus-Christ", en Communio (ed. fr.) XXXVIII, 5 (2012) 106-119; A. Espezel, "Lo cristiano como drama: cristologías dramáticas", en Communio (ed. arg.) 20/1 (2013) 54-75.

60 Ver A. Gesché, Jesucristo, 101. 
Por supuesto, el autor puede delegar al narrador o a determinados personajes la presentación de su propia tesis sobre la identidad de Jesús. Pero justamente, Marcos no quiso hacerlo ${ }^{61}$. En la ausencia de una validación por parte de Jesús, la valoración de la respuesta de Simón Pedro a la pregunta cristológica depende del crédito que le da el lector. Ahora bien, la valoración de Pedro en cuanto personaje es equívoca. Por una parte, el lector lo puede considerar como portavoz oficial del cristianismo, puesto que Jesús lo instituye primero de los “apóstoles" (Mc 3, 16). Por otra parte, poco después de su respuesta, Pedro es presentado como el que tiene pensamientos demasiado humanos y no divinos (8, 33). Incluso su proclamación cristológica no se ve acreditada por Jesús, que reacciona con una orden enérgica de "no hablar acerca de él" (8, 30). La respuesta final a la pregunta cristológica: "Verdaderamente este hombre era hijo de Dios" $(15,39)$, tampoco se puede considerar como una declaración unívoca, fijando la identidad de Jesús, puesto que lejos de ser dada por un personaje autorizado, emana de un extranjero, testigo de una muerte humillante. La impresión general con que el lector cierra el libro de Marcos es de una perplejidad simbolizada por el silencio y el miedo de las mujeres mirróforas $(16,8)$. En fin, el lector, tal como los personajes del relato, está llamado a dar su propia respuesta a la pregunta cristológica.

\section{Una identidad para los demás}

Ahora bien, esta identidad entregada a los demás corresponde perfectamente a otro rasgo de Jesús presentado en las interpretaciones del Nuevo Testamento: su ser para los demás. Este rasgo fue subrayado por Dietrich Bonhoeffer ${ }^{62}$ y Karl Barth ${ }^{63}$, y varios autores de la segunda mitad del siglo xx lo designan con el neologismo de "pro-existencia" ${ }^{4}$.

61 No entro aquí en la cuestión de la autenticidad de la variante que identifica a "Jesucristo" como "Hijo de Dios" en Mc 1, 1.

62 Ver D. Bonhoeffer, Resistencia y sumisión. Cartas y apuntes desde el cautiverio (tr. esp., Esplugues de Llobregat 1969) 224 = "Entwurf für eine Arbeit", en Widerstand und Ergebung. Briefe und Aufzeichnungen aus der Haft (1951) (19ª ed., Gütersloh, 2008) 204: das 'Für-andere-dasein' Jesu.

63 K. Barth, Die Kirchliche Dogmatik, III. Die Lehre von der Schöpfung, 2 (Zürich 1959), apartado $\$ 45.1$, "Jesús, el hombre para los otros hombres", $\$ 45.1$, 242-264. Ver M. Deneken, "Pour une christologie de la pro-existence”, Revue des sciences religieuses 62 (1988) 265-290.

64 Ver por ejemplo el documento de la Comisión Teológica Internacional, Cuestiones selectas de cristologia (1979), III, C, 5 y IV, B, 2.4.

(http://www.vatican.va/roman_curia/congregations/cfaith/cti_documents/rc_cti_1979_cristologia_sp.html) 
Marcos describe a Jesús disponible a todo encuentro, atento a las necesidades de cada uno, no teniendo ni tiempo ni lugar para estar a solas con sí mismo. Declaraciones con el verbo "venir" (Mc 2, 17; 10, 45; Mt 5, 17; 10, 34-35; 11, 19; Jn 9, 39; 10, 10; 12, 46-47) expresan el carácter dinámico de su identidad, determinada por una finalidad que no le concierne a él mismo sino a los demás.

Pablo interpreta la muerte de Cristo como muerte "a favor" de los hombres (hyper, Rm 5, 6-8; 14, 15; 1 Co 15, 3; 2 Co 5, 15.21 etc.). Este ser para los demás incluso puede hacerse un ser en el lugar de los demás (anti, Mc 10, 45): Cristo "se vacía" (Flp 2, 7), renuncia a su identidad propia, a favor de los hombres, en una operación de intercambio (ver por ejemplo 2 Co 8, 9; Ga 4, 4-5).

La entrega de sí a los demás (paradidonai, ver Mc 9, 31) culmina en el gesto de la última cena, donde Jesús, representado metonímicamente por su cuerpo y su sangre, se identifica con el ser entregado en don a los demás, representado por el pan y el vino ofrecidos a sus discípulos, y por la muerte violenta en la cruz. "Este es mi cuerpo [...] Esta es mi sangre [...] derramada por muchos" (Mc 14, 22.24; cf. 1 Co 11, 24-25).

\section{Una identidad desde el Padre}

Si Jesús tiene una identidad determinada por su orientación hacia los demás, es porque la recibe de otro como una misión: según las palabras de Karl Barth, Jesús es "el hombre para Dios" ${ }^{65}$, en el sentido de que, para él, ser hombre coincide con cumplir una función dada por Dios ${ }^{66}$. Esta idea fundamenta la cristología en clave de misión de Hans Urs von Balthasar ${ }^{67}$.

En una misión, una persona, el mandante, "envía" a otra persona, el mandatario, de tal modo que todo lo que diga o haga el mandatario sea atribuido al mandante. Por lo tanto, el mandatario no se presenta a sí mismo, sino que representa al mandante. "No presentarse a sí mismo" significa: el presentante no corresponde a lo presentado. No hay identidad. Esta falta

65 K. Barth, Die Kirchliche Dogmatik, III, 2, apartado $\$ 44$.1, “Jesús, el hombre para Dios”, 64-82.

66 "Jesús es ni más ni menos portador de una función (Träger eines Amtes) [...] es hombre, en cuanto es portador de esta función" (ibidem, p. 66).

67 H. U. von Balthasar, Teodramática, 3, "misión y persona de Cristo", 143-239 = Theodramatik, II, 2, p. 136-238. 
de identidad es paradójica. Por un lado, el enviado, en cuanto representando a otro, suspende su identidad. En el caso absoluto, el enviado no tiene identidad: es pura presentación del no presente, visibilidad del invisible. "El que me recibe, no me recibe a mí sino al que me ha enviado” (Mc 9, 37). Mejor dicho, no es que en lugar de una identidad propia, el enviado tenga la identidad de otro, sino que su identidad propia consiste en representar la identidad de otro, en estar dispuesto a "cumplir la voluntad" del otro ( $\mathrm{Hb}$ 10, 7 = Sal 39, 8-9 LXX), en ser dispuesto por la voluntad del otro. Pero, por otro lado, el mandante ausente, renunciando a presentarse a sí mismo, deja que el mandatario se presente en su lugar y "se lo ha dado todo en su mano" (Jn 3, 35).

El Evangelio de Juan adopta explícitamente una ontología de la misión para presentar la identidad de Cristo (Jn 3, 17.34; 4, 34; 5, 23-24 etc.). Esto explica la paradoja de que en el cuarto Evangelio abundan al mismo tiempo fórmulas de supresión de sí a favor del Padre y fórmulas de afirmación de sí: "Sabréis que Yo soy y que no hago nada por propia iniciativa" $\left(\mathrm{Jn} \mathrm{8,} \mathrm{27)}{ }^{68}\right.$.

Ahora bien, la identidad que consiste en disponerse a hacer la voluntad del Padre es una identidad dinámica. Jesús progresa en esta identidad. De hecho, la forma narrativa de los Evangelios ${ }^{69}$ destaca la estructura progresiva de despliegue de la identidad de Jesús en el desarrollo cronológico de su existencia mortal, y una correspondiente progresión en el conocimiento de esta identidad por parte de los personajes de relato y de sus lectores. Esta doble progresión no es lineal sino que sigue la "estructura inestable de concordancia discordante" característica de una trama narrativa, "entre la dispersión episódica del relato y el poder de unificación desplegado por el acto configurador que es la poiesis misma"70. En el caso de Jesús de Nazaret, esta estructura llega a su nivel más alto de tensión. La muerte, en cuanto máxima solución de continuidad en el hilo existencial, es integrada en el proceso de identificación: "Aun siendo Hijo, de lo que padeció aprendió la obediencia" (Hb 5, 8).

68 Ver los análisis de X. Morales, Dieu en personnes, 39-62.

69 Sobre el concepto de "identidad narrativa", ver Paul Ricoeur en Tiempo y narración III. El tiempo narrado (1985) (tr. esp. de A. Neira Calvo, Madrid 1996), "Conclusiones, 1. La primera aporía de la temporalidad: la identidad narrativa", 994-1002; íDEM, "Lidentité narrative”, en Esprit 7-8 (1988), 295-314, y sobre todo Sí mismo como otro, estudio VI: "El sí y la identidad narrativa".

70 P. Ricoeur, Si mismo como otro, 140. El mismo Ricoeur habla de "identidad dinámica” (ibidem, 141). 
Sin embargo, esta progresión no debe ser necesariamente interpretada en un sentido adopcionista, como si la identidad orientada hacia la voluntad del Padre sucediera a una primera identidad puramente determinada por las condiciones históricas. No se trata de una substitución de identidades, sino más bien de la identificación de la una con la otra. En el tiempo, Jesús progresa hacia la identidad cristológica, tal como, analógicamente, en la eternidad, él procede hacia la identidad filial determinada por el Padre.

Ahora bien, esta determinación de su identidad personal por el Padre es posible, sólo porque el Hijo se entrega con una infinita ausencia de determinación propia. La meditación de la dimensión mediata de la identidad personal de Jesús de Nazaret lleva, por lo tanto, a descubrir que, si bien la identidad personal en los hombres es una determinación máxima de la naturaleza común, la identidad de Jesús es una infinita ausencia de determinación, una posibilidad absoluta de ser determinado por Dios para los hombres.

\section{Identidad retrospectiva}

Si Jesús progresa hacia su identidad personal, ¿cuál es el momento decisivo de este progreso? Las interpretaciones diversas del Nuevo Testamento convergen para decir que la determinación de la identidad personal de Jesús por parte de Dios tuvo su punto culminante en su resurrección. Por lo tanto, la identidad de Jesús es una identidad desde la Resurrección.

\section{Identidad desde la Resurrección}

De hecho, Pablo ${ }^{71}$ proclama que "el que vino al ser según la carne a partir de la descendencia de David, fue definido (oristhentos) como Hijo de Dios con poder según el Espíritu de santidad, a partir de una resurrección de entre los muertos" (Rm 1, 3-4; cf. Flp 2, 9; Hch 2, 36; 1 Tm 3, 16). Si bien, ya "durante los días de su vida mortal" (Hb 5, 7), "Jesús el Nazoreo fue acreditado por Dios con milagros, prodigios y signos” (Hch 2, 22), él logró su identidad decisiva cuando recibió de Dios la vida que supera la limitación de la muerte. A partir de su resurrección, Jesús no tiene otro origen que Dios mismo. Esto es ser verdaderamente Hijo de Dios: "no haber nacido de sangre $[\ldots]$ sino haber nacido de Dios" (Jn 1, 13). Por eso dice Pablo que

71 Los exegetas consideran que, en este pasaje, Pablo recoge un sustrato tradicional. Ver por ejemplo H. Schlier, Der Römerbrief (2a ed., Freiburg - Basel - Wien 1979) 22, nota 21 y 23-27. 
ya no conoce la identidad de Jesús desde su existencia histórica previa a su resurrección, "Cristo según la carne", pero desde la posibilidad que abre su resurrección para una "nueva creación" (2 Co 5, 16-17).

Sin embargo, esta identificación final de Jesús como Cristo e Hijo de Dios elevado al nivel ontológico de "Señor" tiene una validez retrospectiva. Esto explica la decisión de Wolfhart Pannenberg de empezar su tratado de cristología por la Resurrección ${ }^{72}$. La identidad final de Jesús ilumina toda su existencia mortal y revela su estructura "proléptica".

Esta idea se expresa de diversas maneras en la forma narrativa de los Evangelios. Por un lado, el narrador alude al acontecimiento de la resurrección futura como acontecimiento que dará sentido a algo que no se entiende en su momento (ver Mc 9, 9-10; 9, 32; Jn 2, 22; 7, 39). Por otro lado, ciertas escenas son verdaderas anticipaciones de la Resurrección. En la Transfiguración, Jesús "cambia de figura" (metemorphōthēe, Mc 9, 2). Aquí no se trata del mero cambio de la aparencia superficial revestida por un sujeto siempre idéntico a sí mismo. La "figura" es lo que permite de identificar a alguien. Tambien los vestidos blancos resplandecientes (Mc 9,3) sirven, en la estrategia narrativa de Marcos, para permitir una nueva identificación. En cuanto elemento típico de los personajes celestes descritos en los relatos apocalípticos (Dn 7, 9; 10, 5-6; 1 Henoc, 14, 20 [gr.]; 46, 1 [etiop.]; 71, 1 [etiop.]), ellos evocan en particular la figura escatológica del "Hijo del Hombre" (Mc 13, 26; 14, 62). De hecho, el comentario que sigue el acontecimiento apunta hacia la futura "resurrección del Hijo del hombre" (Mc 9, 9). La proclamación por parte de Dios de la identidad de Jesús como su Hijo $(9,7)$ se da, por lo tanto, en un contexto de anticipación de la Resurrección, donde Jesús se identificará plenamente como "Hijo de Dios" e "Hijo del Hombre". Asimismo, los siete "signos" del Evangelio de Juan son anticipaciones de la "glorificación" del Hijo del hombre que tendrá lugar en la "hora" de su elevación en la cruz (ver Jn 2, $11 ; 12,23.28)$.

\section{Identidad escatológica}

Que la identidad de Jesús se decida en su resurrección significa que, durante su existencia mortal, su identidad le venía del futuro. Esta determinación contradice la concepción vulgar de la identidad, donde el hombre se consi-

72 Ver W. Pannenberg, Fundamentos de cristología (1964) (tr. esp., Salamanca 1973) 67-82. 
dera determinado sobre todo por su pasado, su genealogía, su educación, su nacionalidad y su cultura.

Ahora bien, como lo demostró Balthasar ${ }^{73}$, la muerte y resurrección de Jesús coincidieron, para él, con el horizonte escatológico y el cumplimiento final de su identidad. Los evangelistas expresaron esta interpretación escatológica de la resurrección en las declaraciones prolépticas que siempre la atribuyen al "Hijo del hombre", la figura escatológica que "será vista viniendo en las nubes" (Mc 13, 26 = Dn 7, 13). Esto significa que, para Jesús, recibir su identidad desde su resurrección futura es recibir una identidad escatológica.

En cambio, para los que siguen viviendo en la temporalidad mundana, aun después de la resurrección de Jesús, el horizonte escatológico de donde le viene su identidad todavía está en el futuro. Jesús sigue siendo "el que viene", tal como lo esperaba Juan Bautista (Mt 11, 3; cf. Mc 1, 7). En su primera carta conservada, Pablo recuerda a los Tesalonicenses que ellos "esperan el Hijo <de Dios>, <viniendo> de los cielos, el que <Dios> resucitó de entre los muertos, Jesús, el que nos libra de la cólera que viene" (1 Ts 1, 10). La identidad de Jesús presentada por toda la carta es la de una persona que, a partir de su muerte y resurrección ( 1 Ts 4,$14 ; 5,10)$, es objeto de "esperanza" (1 Ts 1, 3), hasta su "venida" escatológica (parousia, 1 Ts 2, 19; 3, 13; 4, 15; 5, 23). Asimismo, la cena del Señor no es sólo "memoria" del pasado, sino que orienta hacia el futuro: con ella, "anunciáis la muerte del Señor hasta que venga" (1 Co 11, 26).

Recibiendo, durante su existencia mortal, su identidad desde el futuro escatológico, Jesús no podía disponer de ella como el hombre dispone de la memoria de su "yo" pasado para identificarlo, en su conciencia, con su "yo" presente. De hecho, en las declaraciones acerca de la futura muerte y resurrección del Hijo del hombre, Jesús habla en tercera persona, como si él no pudiera todavía identificarse completamente, en cuanto "yo", con este "él". "Jesús no se identifica inmediatamente con el Hijo del hombre: será éste sólo cuando habrá totalmente cumplido la misión que Dios le entregó”74.

73 Teodramática, 3, "escatología y dogmática”, 106-114 = Theodramatik, II, 2, 99-106.

74 B. SesвoüÉ, “Christologie fondamentale”, en Revue théologique de Louvain 48 (2017) 217-242, aquí 228. En el tercer apartado de su artículo, Sesboüé subraya la necesidad de un "itinerario" para acceder a la identidad de Jesús, abierto por la propia "pedagogía" elegida por Jesús. "Peda- 
Esto confirma que la identidad de Jesús, en cuanto mediata, no reposa principalmente en la autoconciencia, como ocurre en el concepto idealista del sujeto espiritual, sino en la correlación entre una apertura receptiva y una determinación no disponible.

Del mismo modo, y conforme al desfase entre el horizonte escatológico de Jesús y el horizonte escatológico de los otros hombres, los creyentes siguen percibiendo la identidad del resucitado como una identidad desde el futuro y, por lo tanto, no disponible a su conocimiento, sino sólo acogida por su fe. Sólo en el instante escatológico se cumplirá para ellos la identificación personal de Jesús, paralelamente a la identificación escatológica de Dios, como lo subraya Wolfhart Pannenberg ${ }^{75}$. La identificación entre la misión temporal y la persona de Cristo es una "ecuación progresiva"76.

\section{Identidad paradójica}

En su concepto vulgar, la identidad personal vincula los momentos sucesivos de la existencia, desde el nacimiento hasta la muerte. La identidad personal consiste entonces en la prolongación en el tiempo, desde el pasado hacia el futuro. Si bien la individualidad y la conciencia de Jesús, durante su existencia mortal, poseían probablemente esta identidad como prolongación desde el pasado, su personalidad poseía una identidad que le venía del futuro. Por lo tanto, el concepto cristológico clásico de "pre-existencia" debe ser criticado y correctamente interpretado.

\section{Deconstrucción del concepto de pre-existencia}

El término "pre-existencia" no se encuentra en el Nuevo Testamento ${ }^{77}$, pero sí su concepto, y además en sus documentos más antiguos. La carta de Pablo a los Filipenses incluye un pasaje que muchos exegetas consideran como la

gogía” es la palabra clave de la propuesta cristológica de Sesboüé, Pédagogie du Christ. Éléments de christologie fondamentale (París 1994).

75 Ver por ejemplo Teología sistemática, I (tr. esp., Madrid 1992) 358.

76 E. DuRand, L'Offre universelle du salut en Christ (París 2012) 184-192. Ver X. MoRales, Dieu en personnes, 177-181.

77 De una búsqueda en el corpus en línea del Thesaurus Linguae Graecae, resulta que el primer

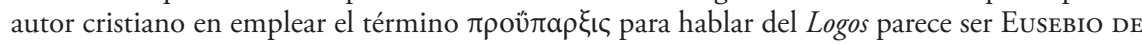
Cesarea (ver por ejemplo Teología eclesiástica, II, 21, 2 a propósito de Jn 8, 58 y III, 2, 24 a propósito de Pr 8, 22). 
reescritura de un sustrato previo ${ }^{78}$ (Flp 2, 6-11): Cristo, "siendo en forma de Dios [...] se vació de sí mismo, tomando forma de siervo". Este esquema supone - dos movimientos: desde la forma de Dios a la forma de siervo, y desde la "humillación" al nombre encima de todo nombre, - y tres estados sucesivos: 1) una existencia inicial, la "pre-existencia", 2) una existencia delimitada por nacimiento y muerte, 3) una "post-existencia” escatológica. La finalidad de este esquema parece ser la identificación del estado final de Jesús con su estado inicial ${ }^{79}$.

Si bien los evangelistas sinópticos no usan el concepto de pre-existencia, el prólogo del Evangelio de Juan habla de una entidad que pasa (egéneto, Jn 1, 14) de un estado inicial, donde es llamada "palabra" (logos, Jn 1, 1), a un segundo estado, donde es llamada "carne" (sarx, Jn 1, 14) y "unigénito" (monogenès, Jn 1, 14). Este segundo estado coincide con la existencia histórica de "Jesucristo" (Jn 1, 17). El resto del Evangelio cuenta la vuelta de este segundo estado al estado inicial: "el Dios unigénito que era en el seno del Padre" (Jn 1, 18) "regresa al Padre" (Jn 16, 28).

Los concilios de Nicea (325) y Éfeso (431) impusieron una interpretación del esquema tripartito en clave de identidad prolongada en el tiempo. Tanto la llamada "cristología del logos-sarx", como la "cristología del logos-anthrōpos" fundamentaron la identidad de Jesús en un elemento, el logos, responsable de la permanencia substancial a través de los cambios de estado. La discordancia con sí mismo padecida en el estado intermedio es sólo provisoria e imputada a la acogida de un elemento accidental, sōma, sarx, o anthrōpos. Acerca de este punto, la divergencia entre las dos maneras de vincular el elemento substancial y el elemento accidental ("unión según la

78 Ver por ejemplo S. Fernández Eyzaguirre, Jesús. Los orígenes históricos del cristianismo: desde el año 28 al 48 d.C. (5ª ed., Santiago 2011) 110-113.

79 Esta interpretación de la aparición del concepto de pre-existencia se encuentra, por ejemplo, en M. Hengel, El Hijo de Dios. El origen de la cristología y la historia de la religión judeo-helenistica (tr. esp., Salamanca 1979) p. 96: "un cierto interés protológico cuadraba perfectamente con la conciencia escatológica de la comunidad primitiva”, en el documento de la Comisión Teológica Internacional, Teología, cristología y antropología (1982), II, A, 2: "Desde el acontecimiento escatológico de Jesucristo se pasa a su significación protológica, y también viceversa", o en S. Fernández Eyzaguirre, Jesús, 111: "la doctrina de la preexistencia se desarrolló como una exigencia interna de la cristología de la exaltación". 
hypóstasis" ${ }^{80}$ o "conexión en una única persona" ${ }^{81}$ ) es sólo relativa. La arcaica "cristología del pneuma", partiendo de la misma distinción entre dos elementos, identificaba el elemento substancial con "el hombre" o "la carne", y el elemento accidental, el pneuma, lo que reducía la prolongación de la identidad a los límites humanos.

Es verosímil la influencia de las figuras de mediación cósmica de la literatura bíblica sapiencial o de las figuras escatológicas de la literatura judía intertestamentaria sobre el concepto cristológico de pre-existencia ${ }^{82}$. Las figuras de mediación aseguran que Dios, a pesar de intervenir en el mundo, queda más allá del mundo. Por lo tanto, es necesario que existan, junto a Dios, desde el origen del mundo. Del mismo modo, las figuras escatológicas, en cuanto figuras reveladas con anticipación al pueblo de Dios para animar su esperanza en el futuro, se consideran como ya presentes pero todavía ocultas en el cielo. Sin embargo, alegar esta influencia para proponer una interpretación atenuada de la pre-existencia como "pre-destinación antes de los siglos" (1 Co 2, 7; ver Sb 8, 23), o sea, como pre-existencia solamente ideal, y no real, tal como en el caso de aquellas figuras, no remueve el problema mayor, el de una interpretación temporal.

De hecho, si la pre-existencia es un primer segmento temporal de existencia que precede a otro segmento temporal de existencia, Jesús vive un caso de metempsicosis, y su conciencia mortal tendría que contener recuerdos de su existencia previa, tal como el Buda se acuerda, después de su iluminación, de la serie de sus existencias previas, contadas en los Jātakas. Ahora bien, no se encuentra ninguna huella en el Nuevo Testamento de "recuerdo de una existencia pre-natal”83, a menos que se interprete así versículos como: "Lo que he visto junto al Padre, esto es lo que pronuncio" (Jn 8, 38; ver 8, 26.28.40 y 3,11$)$. Sin embargo, estos versículos se interpretan mejor en el contexto de la cristología de misión. La única manera de explicar la ausencia

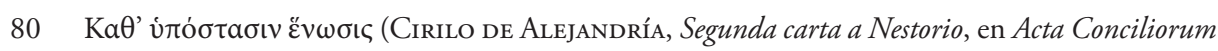
Oecumenicorum, I, 1, 1, doc. 4, 6 [ed. Ed. Schwartz, Berlín - Leipzig 1927] 28, 1. 7).

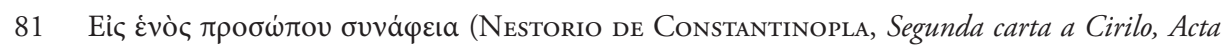
Conciliorum Oecumenicorum, I, 1, 1, doc. 5, 6 [ed. Ed. Schwartz, Berlín - Leipzig 1927] 30, 1. 19-20).

82 Ver M. Hengel, El Hijo de Dios, 93-106.

83 Die Erinnerung an eine vorgeburtliche Existenz (H. U. von BaLthasar, Theodramatik, II, 2, 234, mi traducción. La traducción en Teodramática, 3, 236: "no se requiere traer a la memoria [...] una existencia premundana”, es errónea). 
de "recuerdos pre-natales" sería suponer un muro impermeable entre los contenidos de conciencia de la primera existencia, almacenados en la memoria, y la conciencia actual de Jesús, o incluso entre dos conciencias en Jesús. Por ejemplo, G. O'Collins, a pesar de su postura crítica acerca del concepto de pre-existencia, supone en el único sujeto Cristo dos conciencias correspondiendo a sus dos naturalezas ${ }^{84}$. Ahora bien, esta hipótesis desconecta demasiado la identidad personal de la autoconciencia ${ }^{85}$. Si bien se propuso más arriba una desconexión parcial entre la conciencia de Jesús y su identidad personal que, viniéndole desde el futuro, no le es inmediatamente disponible, no se puede, sin embargo, negar que "la conciencia de Jesús participa de la singularidad y de la índole misteriosa de su Persona" ${ }^{86}$. La distinción entre individuo, sujeto espiritual y persona debe ser considerada como una progresión cumulativa.

\section{Construcción del concepto de trans-existencia}

¿Cómo interpretar el concepto de pre-existencia de manera que no caiga bajo las absurdidades que conlleva su comprensión dentro de un marco cronológico?

Si efectivamente el concepto de pre-existencia se dedujo de la Resurrección como inicio de una existencia escatológica, la comprensión correcta de ésta depende de la comprensión correcta de aquella. Los documentos del Nuevo Testamento dan evidencia de que la resurrección de Jesús no fue percibida como una reanimación ni, entonces, como una prolongación de la vida de Jesús después de una discordancia superada. La existencia del resucitado es otra existencia que la existencia mortal de Jesús. Por eso notan Lucas y Juan que los discípulos tuvieron dificultades en reconocerle (Lc 24, 16; Jn 20, 14; 21, 4). Tal como en la Transfiguración, Jesús resucitado cambia de forma de existencia. Esta existencia, por

84 G. O'Collins, en Christology: A Biblical, Historical, and Systematic Study of Jesus (2a ed., Oxford 2009), habla de dos "mentes" o "subsistemas cognitivos" o "conciencias" (257). Sobre la alternativa entre una o dos conciencias en Cristo, ver la síntesis de W. KASPER, Jesús, el Cristo (tr. esp., 12a ed., Salamanca 2002) 393.

85 Ver G. O’Collins, Christology, 243-244, y la distinción sofisticada a la que esta tesis conduce, entre person, personality y personhood (256).

86 Comisión Teológica Internacional, La conciencia que Jesús tenía de sí mismo y de su misión (1985), Introducción.

(http://www.vatican.va/roman_curia/congregations/cfaith/cti_documents/rc_cti_1985_coscienza-gesu_sp.html) 
lo tanto, no se puede calificar sin más de post-existencia. Se sitúa en otro nivel ontológico, expresado por la "exaltación" a la forma de existencia propia de Dios, con "gloria” y "señorío" absoluto. Desde ahí se deduce que esta existencia trascendente no se relaciona a la existencia mortal de manera cronológica.

La pre-existencia debe interpretarse de la misma manera. No está cronológicamente relacionada a la existencia mortal de Jesús. No se trata de prolongar la existencia mortal de Jesús, esta vez en dirección del pasado ${ }^{87}$. Se trata de llevar a cabo la identificación de Jesús con su existencia escatológica de tal modo que el "venir desde el futuro" de su identidad durante su existencia mortal sea ahora comprendida como un "venir desde un más allá del tiempo". Por lo tanto, G. O’Collins propone sustituir a "pre-existencia” el neologismo "trans-existencia" 88.

En este contexto, como lo nota Robert W. Jenson" ${ }^{89}$, el "era" de Jn 1, 1 debe ser interpretado a partir de la fórmula paradójica de Jn 8, 58, donde un hecho al presente, "yo soy", precede ("antes que") un hecho pasado, "Abraham fue". Igualmente, el esquema tripartito de Flp 2 no describe tres segmentos cronológicos en la existencia de Jesús. Expresa más bien cómo la identidad de Jesús desborda las limitaciones históricas.

Esta dimensión trascendente de la identidad de Jesús encuentra su marco interpretativo más relevante en la analogía de la misión. Formulaciones como Ga 4, 4-5 apuntan claramente, no a un segmento cronológico previo al envío - una época en que el mandatario todavía no estuviera contratado por el mandante para su misión- sino al origen de la misión. Cuando Pablo afirma: "Dios envió a su Hijo" (Ga 4, 4), él interpreta la existencia de Jesús, gracias a su final, como una misión, y una misión cuyo origen está más allá del "mundo" y sus "elementos" (Ga 4, 3).

Finalmente, la identidad de Jesús se revela como una identidad paradójica, puesto que, en vez de resultar de la coincidencia entre dos términos iguales, resulta de la coincidencia entre dos términos absolutamente

87 En un sentido semejante, dice W. KASPER, Jesús, el Cristo, 282: "No se trata [...] de prolongar el tiempo hasta introducirlo en la eternidad, sino de fundamentar la historia de la salvación en la eternidad de Dios".

89 R. W. Jenson, Systematic Theology, vol. 1, The Triune God (New York - Oxford 1997) 139. 
desiguales $^{90}$ : las limitaciones mundanas propias a toda existencia humana y la infinidad existencial propia al ser trascendente de Dios. Si Jesús, en cuanto individuo de la especie humana, es definido, entre otros, por su origen biológico, su "descendencia de David" (Rm 1, 3), su "venida al ser a partir de una mujer" (Ga 4, 4), en cuanto persona, es definido por su origen "desde la substancia del Padre"91.

Aquí es donde se puede dar un valor de anticipación cristológica a las figuras bíblicas de mediación entre la trascendencia de Dios y la inmanencia mundana, como el Espíritu de Dios, su Sabiduría o su Palabra, y finalmente, a la recuperación de la figura filosófica del logos. Aquí también es donde se puede recuperar la interpretación idealista de la persona de Jesús de Nazaret como identidad de lo infinito con lo finito: "que lo verdaderamente infinito llegase a lo finito" ${ }^{2}$. La coincidencia entre lo infinitamente opuesto, lo trascendente y lo inmanente, en cuanto coincidencia, produce una identidad que, en cuanto coincidencia entre opuestos, es paradójica.

\section{Cristo no es otro que Jesús}

Una descripción fenomenológica de la dimensión paradójica de la identidad de Jesús tendría como punto de partida la siguiente constatación: los que se cruzan con Jesús "quedan asombrados" (explèssesthai, Mc 1, 22; thambeisthai, Mc 1, 27; existasthai, Mc 2, 12; phobeisthai, Mc 4, 41; thaumazesthai, Mc 5, 20 etc.). Algo les escapa: “¿Qué es esto?” (Mc 1, 27); “¿Quién es éste?” (Mc 4, 41); “¿De dónde le viene esto?” (Mc 6, 2).

Los observadores perciben que Jesús es más que lo que aparece. Pero para ser percibido, este "más" debe darse dentro de lo que aparece. Aquí está la paradoja: al mismo tiempo, lo que se da de Jesús no coincide con (es más que) lo que aparece de él, y coincide con (se da dentro de) lo que aparece. Lo que no coincide es la "trans-existencia", pero esta trans-existencia se da en la existencia mortal.

De hecho, de la crítica de la interpretación cronológica de la pre-

90 G. O'Collins, en el contexto de su tesis de "dos mentes" en Cristo, subraya que estas "dos mentes existen en niveles infinitamente diferentes" (Christology, 258).

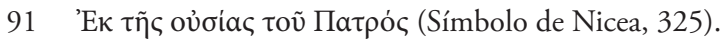

92 Fr. W. J. Schelling, Lecciones sobre el método de los estudios académicos (1803) (tr. esp., Madrid 1984) 138. 
existencia resulta que la identidad personal de Jesús no se da "antes" ni "después", o sea, "fuera de" la existencia mortal de Jesús. No queda apoyada en un elemento substancial (hypóstasis) prolongándose "antes", "detrás” y "después" de la existencia mortal de Jesús, un Logos alternativamente "fuera de la carne" (Logos asarkos) y "encarnado" (ensarkos). Concebir un "Logos fuera de la carne" (Logos asarkos ${ }^{93}$ ) es tan absurdo como concebir Dios antes de crear el mundo: Dios, eternamente, se determinó a crear el mundo. Dios, eternamente, es Dios en relación con los hombres ${ }^{94}$. Dios, eternamente, engendró a su Hijo. Dios, eternamente, envió a su Hijo a compartir la existencia de los hombres, y esto, no en un sentido sólo ideal de una predestinación, sino en un sentido real.

Aquí es donde se recupera la intuición de Balthasar: la identidad personal de Jesús es, ni más ni menos, la identidad del Hijo de Dios en cuanto ésta se recibe exclusivamente del Padre, o sea, en cuanto ésta consiste en originarse exclusivamente del Padre. En palabras de Robert W. Jenson: "Jesús es el Hijo / Logos de Dios en relación con el Padre, y no por una relación con una realidad coordinada, 'el Hijo / Logos' "95. Y recíprocamente, "la segunda identidad de Dios es directamente la persona humana de los Evangelios, en cuanto es el que está orientado hacia el Padre (stands to the Father) en la relación de ser eternamente engendrado por él"96.

\section{ConClusión}

Al momento de concluir, es preciso recordar la finalidad que se daba en este trabajo. Sólo se pretendía aclarar el concepto de identidad personal que se debía usar para poder plantear la pregunta: “Quién es Jesús de Nazaret?” Es cierto que, en el proceso, fue necesario anticipar algunos elementos de respuesta a esta pregunta, pero suspendiendo el juicio acerca de su veracidad.

93 Las críticas de Balthasar ("no existe [...] ningún momento en que el Logos pueda ser considerado como asarkos", Teodramática, 3, 236) y R. W. Jenson ("Once more the Logos asarkos", International Journal of Systematic Theology 13/2 [2011] 130-133), entre otros, derivan de K. Barth, Die Kirchliche Dogmatik, IV, 1 (Zürich 1960) 54-56.

94 Dios, en su "libre gracia", "no quiere ser Dios, y no es Dios, sino como Dios del hombre" (K. Barth, Die Menschlichkeit Gottes [Zürich 1956] 3 - mi traducción). Ver la famosa y controvertida interpretación de Barth dada por B. L. McCormack, "Grace and Being: The Role of God's Gracious Election in Karl Barth's Theological Ontology", en The Cambridge Companion to Karl Barth (ed. J. Webster, Cambridge 2000) 92-110.

95 R. W. Jenson, “Once more the Logos asarkos", 130.

96 R. W. Jenson, Systematic Theology, vol. 1, 137. 
Las formulaciones de este trabajo siempre deben ser tomadas en el sentido: "En el caso de que fuera verdad que Jesús es $\mathrm{N}$, entonces, hay que entender de tal manera que él sea el que es."

El concepto de identidad personal al que se llega coincide con el requisito enunciado al principio: respeta la singularidad del objeto para el cual se usará hasta tal punto que escapa en muchas dimensiones a los conceptos comunes de identidad personal. Jesús trasciende la manera de ser sí mismo de la persona humana, porque sólo así es posible pensar que, en él, lo trascendente coincide con lo inmanente.

Que la concepción tradicional de la unión entre dos "naturalezas" no logre expresar cabalmente la identidad de Jesús, lo demuestra la oscilación histórica entre disyunción y confusión ${ }^{97}$. Ya se ha acusado muchas veces a la cristología del concilio de Calcedonia su falta de dimensión dinámica ${ }^{98}$. Las dificultades de la cristología de las dos naturalezas resultan de que, en ella, se intenta definir la identidad de Jesús a partir de una unión entre elementos, sin tener en cuenta la desproporción infinita entre estos elementos. Ahora bien, la identidad se debe pensar, no como una unión que resuelve esta desproporción, sino como una coincidencia que mantiene la desproporción, una identificación paradójica.

Además, llegar a un concepto singular de identidad personal para la cristología permite una conexión perfecta con la teología trinitaria, donde el concepto de identidad personal también sólo puede ser analógico. Si, en el caso de la persona humana, y, en cierta medida, de Jesús, la identidad personal asume la identidad individual y la identidad de la conciencia, no puede ser el caso de la persona divina. La persona divina no es un individuo en el sentido de la última subdivisión de un género, puesto que Dios no es un género. La persona divina tampoco es un individuo en el sentido de la materialización de una forma, puesto que Dios no es material. El único principio de distinción en Dios es la relación de origen ${ }^{99}$, fundamento de la identidad personal. En la persona divina, entonces, la identidad personal tiene lugar de identidad individual. La persona divina es una persona no individual ${ }^{100}$. En

97 Ver, entre otros, W. KaSper, El Dios de Jesucristo (7ª edición, 1982) (tr. esp., Salamanca 2005) 201.

98 Ver, entre muchos, W. Kasper, Jesús, el Cristo (12 edición, 1998) (tr. esp., Salamanca 2002) 381.

99 Tomás de Aquino, Suma de teología, Ia, q. 29, a. 4, resp.

100 Ver X. Morales, Dieu en personnes, 188-190. 
cuanto a la identidad de la conciencia, si bien es difícil concebir una persona divina que sea persona sin ser sujeto espiritual, tanto Karl Barth como Karl Rahner rechazaron la idea que haya más de un sujeto en Dios ${ }^{101}$. Esta postura no parece compatible con una cristología del envío, donde, para que el Hijo acepte de no presentarse a sí mismo sino de representar al Padre, hacen falta dos "sí".

Ahora bien, esta definición de la persona divina como relacional y no individual se predica analógicamente a cada una de las tres personas ${ }^{102}$. El caso de la persona del Hijo es complejo. El Hijo, por su identificación como Jesús de Nazaret, sí tendría una identidad individual, a la diferencia del Padre y del Espíritu Santo, puesto que asume las determinaciones biológicas y culturales que constituyen la identidad individual de Jesús. Y, cualquiera que sea la respuesta a la pregunta por el número de conciencias y de sujetos divinos en la Trinidad, el Hijo, siempre por su identificación como Jesús de Nazaret, también tendría una identidad de conciencia, puesto que asume los contenidos de conciencia que constituyen la identidad de Jesús en cuanto sujeto espiritual.

Si esto es correcto, habría que corregir lo que se dijo más arriba acerca de una "infinita ausencia de determinación propia" como contenido de la identidad de la persona del Hijo. Conforme a esta idea, la identidad personal del Hijo es eternamente determinada por la decisión de ser sí mismo, no a partir de sí mismo sino a partir de la determinación dada por el Padre. Pero la identificación del Hijo con Jesús impide concebir esta identidad personal como reducción de sí a una función asignada por Dios, como alienación de sí por la obediencia al Padre, o como un puro vacío, como en la interpretación radical de la kénōsis de Flp 2 por parte de Balthasar, que le lleva a hablar de la "falta de sí (Selbstlosigkeit) de las personas divinas como puras relaciones en la vida intradivina del amor" ${ }^{103}$. La identidad personal de Jesús

101 K. Barth, Dogmatik, I. Die Lehre vom Wort Gottes, 1 (Zürich 1955), tesis del apartado 9, 367; K. Rahner, "El Dios trino como principio y fundamento trascendente de la historia de la salvación” en Mysterium Salutis. Manual de teología como historia de la salvación, vol. II, t. I (1965), dir. J. Feiner y M. LöHrer (tr. esp., Madrid 1969) 360-449, particularmente 398 y 411-412. Ver el comentario en X. Morales, Dieu en personnes, 12-16.

102 Sobre el sentido analógico de persona en la Trinidad, ver X. Morales, Dieu en personnes, 153-181.

103 H. U. von Balthasar, Herrlichkeit, III, 2, 2, 198 (mi traducción). Si bien Selbstlosigkeit puede tener un sentido moral como "altruismo", propuesto en la traducción castellana publicada (Gloria, 7, 176), preferí una traducción literal que le confiere un sentido ontológico coherente con la teología de Balthasar. 
no es vacía, puesto que asume toda la serie de propiedades de su identidad individual y toda la serie de contenidos de conciencia de su identidad de sujeto espiritual.

Esta última corrección es confirmada por una perspectiva fenomenológica. El Padre no podría reflejarse en su Hijo como en su imagen si el Hijo fuese pura trasparencia, tal como un rayo de luz no puede ser reflejado por un objeto si no le opone ninguna opacidad. No se trata de llegar a decir que Dios necesitaba la opacidad de una existencia mundana para reflejarse en su Hijo. Sin embargo, sí se podría decir que el Hijo no puede ser pura apertura libre a la determinación del Padre sin el correlato de una determinación concreta. No puede ser el enviado del Padre sin un contenido concreto del envío, y esta determinación y este contenido eternamente incluyen la humanidad de Dios.

Del mismo modo, si, como lo afirma Balthasar, el Hijo de Dios es "persona arquetípica" (urbildliche), y las personas humanas "reciben de él su identidad personal" ${ }^{104}$, una interpretación de esta identidad como pura función asignada por Dios presentaría el peligro de reducir la persona al rol que juega en la sociedad, bien sea la sociedad de los hijos del reino que viene. La persona, entonces, no existe "por sí mismo". Desaparece la dignidad de la persona humana según la cual nadie jamás puede ser sólo un medio sin ser un fin en sí. Asimismo, una interpretación de la identidad filial como pura obediencia al Padre podría llevar a una moral y una espiritualidad infantilizantes. Un hombre que, adulto, siguiera dependiendo de sus padres para todos los aspectos de su vida, lo consideraríamos como candidato privilegiado para una psicoterapia. Finalmente, la identidad filial no se puede interpretar como una eliminación de todo sí propio, en un progreso más allá de las determinaciones materiales ("individuo") e inteligibles ("yo") hacia el único "sí" divino. Dios mismo quiere la pluralidad de los individuos ${ }^{105} \mathrm{y}$ busca sujetos espirituales para poder "hablar cara a cara como un hombre con su amigo" (Ex 33, 11).

\section{Nota SUBSIDIARIA: A PROPÓSITO DE UNVORDENKLICH EN HANS URS VON BALTHASAR}

Si bien Balthasar, en el marco de la singularidad de Cristo, repite que es imposible "pensarla exhaustivamente" (unausdenkbar), muchos intérpretes del

104 H. U. von Balthasar, Theodramatik, II, 2, 184. Ver también el término de Urperson (Theodramatik, II, 2, 487).

105 Tomás de Aquino, Suma de teología, Ia, q. 47, a. 1, resp. 
gran teólogo asignan también a esta temática la palabra unvordenklich, que tendría, en Balthasar, el sentido de "lo que no se puede concebir antes que ocurra”. Se lee, por ejemplo, en la traducción castellana de la trilogía, que la identidad entre el "yo" de Jesús y su envío en misión por parte del Padre es "algo im-prepensable" 106 , o que el amor que existe entre el Padre y el Hijo es algo "de antemano impensable" 107.

Ahora bien, de una lectura sistématica de los pasajes en que Balthasar emplea la palabra unvordenklich resulta que el teólogo le da el sentido, no de "lo que no se puede pensar antes de...", sino de "lo antes de que no se puede pensar algo", lo que la edición francesa tradujo correctamente con immémorial, y que la edición castellana también propone en la mayoría de los casos $^{108}$. El propio Balthasar apunta hacia este significado cuando glosa el adjetivo con "antes de la fundación del mundo"109 (Ef 1, 4), o con von jeher ${ }^{110}$ ("desde siempre") ${ }^{111}$. Además, este es el sentido común de la palabra alemana: sehr weit zurückliegend ${ }^{112}$.

En conclusión, cuando Balthasar emplea unvordenklich en el contexto cristológico, subraya que no se puede concebir, ni se dio realmente un tiempo en que Jesús no identifica su "yo" con la misión recibida del Padre. En el contexto trinitario, subraya, igualmente, que no se puede concebir, ni se dio realmente un tiempo en que el Padre no haya engendrado al Hijo.

Que, en cambio, Balthasar no use unvordenklich con el sentido de que "no se podía pensar una realidad antes que se diera" no significa, sin embargo, que no exprese, de otras maneras, este concepto. Pero esto es otro problema.

106 H. U. von Balthasar, Teodramática, 3, 212 (con guión) = Theodramatik, II, 2, 209.

107 H. U. von Balthasar, Teológica, 2. Verdad de Dios, 134 = Teologik, II, 126. Ver también, entre muchos ejemplos, M. Schulz, "The Trinitarian Concept of Essence and Substance", en Rethinking Trinitarian Theology: Disputed Questions And Contemporary Issues in Trinitarian Theology, G. Maspero y R. J. Woźniak (ed.) (T\&T Clark, 2012) 146-176, aquí p. 162: that which we cannot think of in advance.

108 H. U. von Balthasar, Teodramática, 3, 176: "desde siempre" = Theodramatik, II, 2, 171;

109 H. U. von Balthasar, Theodramatik, II, 2, 242. En este caso, la edición castellana traduce simplemente: "antes del tiempo" (Teodramática, 3, 243). La traducción francesa propone: de temps immémorial.

110 H. U. von Balthasar, Teologik, II, 127.

111 H. U. von Balthasar Teológica, 2, 136.

112 https://www.duden.de/rechtschreibung/unvordenklich consultado el 7 de marzo 2019. 